\title{
ARTÍCULO
}

\section{El europeísmo y sus retos democráticos en el marco adverso del neoliberalismo global: cultivo del ethos humanista de Europa y renovación del contrato sociopolítico}

\section{Europeanism and its democratic challenges in the adverse global neoliberalism: cultivation of the humanist ethos of Europe and renewal of the socio-political contract}

\author{
Joan Alfred Martínez i Seguí \\ Departamento de Filosofía del Derecho y Moral \\ Universitat de València
}

Fecha de recepción 31/01/2019 | De aceptación: 03/06/2019 | De publicación: 27/06/2019

\begin{abstract}
RESUMEN.
¿Cuáles son los valores que han de sustentar el incierto futuro de la Europa del siglo XXI inmersa en un mundo multipolar en gestación? Metodológicamente desde una hermenéutica fenomenológica crítica con vocación normativa, el artículo intenta dar respuesta a tal pregunta mediante dos objetivos concretos. Primero, a partir del acervo común de los humanismos democráticos asentado tras la Segunda Guerra Mundial por el europeísmo político, establecer los valores y principios que, a modo de ética pública, deberían regir la imperiosa renovación del contrato sociopolítico de las democracias europeas. Y segundo, diagnosticar algunos de los impedimentos a este deseable desarrollo de las democracias europeas provenientes tanto del pensamiento hegemónico neoliberal como de las variadas reacciones populistas e iliberales surgidas en su contra.
\end{abstract}

\section{PALABRAS CLAVE.}

europeísmo, humanismos democráticos, federalismo, neoliberalismo y populismos iliberales.

\section{ABSTRACT.}

What are the values that will sustain the uncertain future of Europe immersed in a multipolar world in gestation? Methodologically from a critical phenomenological hermeneutics with a normative vocation, this text tries to answer this question by means of two concrete objectives. First, based on the democratic humanisms established after the Second World War by political Europeanism, to establish the values and principles that, as a public ethics, should govern the imperious renewal of the sociopolitical contract of European democracies. And second, to diagnose some of the impediments to this desirable development of the European democracies coming from both the neoliberal hegemonic thought and the varied populist and illiberal reactions that have arisen against it.

\section{KEY WORDS.}

Europeanism, democratic humanisms, federalism, neoliberalism and illiberal populisms. 
Sumario: 1. Introducción; 2. Valores y principios del ethos europeo como fundamentos del contrato sociopolítico; 3. La tradición de los humanismos democráticos y la cultura política federalista como alternativa al neoliberalismo; 3.1 . Movilización ciudadana de carácter permanente e institucionalizado; 3.2. Articulación de una ética pública de inspiración humanista y federalista; 3.3. Reformulación actualizadora de los plurales humanismos democráticos; 4. Neoliberalismo global y reacciones políticas populistas, autoritarias e iliberales: impedimentos a una regeneración de las democracias europeas; 4.1 El neoliberalismo global: marco adverso a una vindicación del ethos político-cultural europeo; 4.2. Los peligros de distintos extravíos sociopolíticos: las reacciones políticas populistas, autoritarias e iliberales; 5 . Bibliografía.

\section{Introducción}

Los últimos comicios europeos celebrados el 26 de mayo de 2019 no han sido, a todas luces, unas elecciones intrascendentes de las que cabría pasar página rápidamente. Y ello, aunque la derecha radical antieuropeista no ha conseguido su propósito de obtener una representación suficiente para garantizar el bloqueo institucional del Parlamento Europeo. Antes bien, la opinión pública europea ha vivido la confrontación partidista de la campaña electoral y los propios resultados del escrutinio final no tanto como una elección ordinaria de candidatos parlamentarios sino, sobre todo, como un auténtico reto a la cultura política democrática de Europa, es decir, como un desafío a los valores y principios que rigen el Estado social y democrático de Derecho amparado por las instituciones de la UE. En diciembre de 2018, cuando Franz Timmermans fue elegido como candidato socialista a presidir la Comisión Europea en el congreso de Lisboa, ya avisó de que "éstas no son elecciones ordinarias. Estas elecciones decidirán el alma de Europa [...] necesitamos firmar un nuevo contrato social con los ciudadanos de Europa". ${ }^{1}$ Ciertamente, cualquier demócrata europeo podría afirmar, con inquietud y desasosiego, que el "alma" de Europa -su ethos político-cultural pero también jurídico, unido intrínsecamente al Estado constitucional- ha estado en riesgo de naufragar ante las amenazas de un pujante estatalismo autoritario abanderado por la extrema derecha poplista.

En medio del debate público, el ethos humanista de Europa se erige pues en tema central aunque no novedoso, ya que siempre ha estado latente en el marco del europeísmo político cobrando rabiosa actualidad de forma intermitente en ocasión de las cíclicas crisis padecidas por el proyecto institucional

\footnotetext{
1 MASDEU, J.; "Franz Tirmmermans, el holandés que quiere reformar Europa", La Vanguardia, 18 de mayo de 2019 [consulta en Internet: 1/6/2019]: https:/www.lavanguardia.com/internacional/20190518/462299422232/franz-timmermans-europa-comision-europeaelecciones.html
} 
de construcción europea. En él, de forma agonal e incluso agónica, ${ }^{2}$ convergen múltiples factores, demasiadas veces considerados de modo disperso y fragmentario desde un prisma académico y científico, pero que requieren urgentemente de planteamientos de carácter integral, interdisciplinar y de interrelación de conceptos y realidades socioculturales y político-jurídicas, a riesgo de caer incluso en una visión panorámica que parezca rayar en lo generalista. Este análisis integral del fenómeno es el que postula José Antonio Pérez Tapias, buen exponente del pensamiento de izquierdas, cuando propone una resistencia activa a la autonegación de Europa en su último libro La Europa desalmada, publicado oportunamente en coincidencia con la celebración de estas últimas elecciones europeas. Una línea de estudio que, en todo caso, no carece de una literatura clásica de referencia -relativamente abundante- ${ }^{3}$ y que, además, ya venía siendo trabajada con denuedo en tiempos recientes desde ópticas diversas, ${ }^{4}$ especialmente desde un humanismo cristiano abierto al diálogo plural y al compromiso social. ${ }^{5}$

A título pues de contribución a esta reflexión doctrinal y científica, con una marcada trascendencia sociocultural en el trasfondo de muchas controversias políticas actuales, es donde cabe ubicar las líneas del presente artículo. Y ello desde una metodología deudora del giro lingüístico de la filosofía política contemporánea hacia una teoría política aplicada y aplicable en el contexto sociohistórico en que se formula; una metodología explicitada por medio de una razonabilidad práctica que aspira a orientar las conductas de los ciudadanos con una vocación normativa y, por ende, abierta a la contingencia de los hechos humanos y al conflicto, sin perder la orientación hacia unos principios de justicia universales que enmarquen la cultura política de las democracias. En definitiva, el estilo de filosofar que se usa aquí, siguiendo el trazo de Paul Ricoeur, es el de una razón práctica de carácter intersubjetivo y, más concretamente, el de una hermenéutica fenomenológica crítica, que aúna, en tensión continua, el polo metodológico lógico-empírico de la modernidad con el polo ontológico o

\footnotetext{
${ }^{2}$ Cabe rememorar aquí el acongojado lamento sobre la situación de Europa que, en circunstancias distintas y aún más graves, profirió María Zambrano en su escrito "La agonía de Europa" [1940]. Cf. ZAMBRANO, M; La agonía de Europa, Madrid, Trotta, 2000, pp. 2342.

${ }^{3}$ En cuanto a la construcción de la idea de Europa y a la aportación de las distintas fuentes culturales que la conforman como matriz civilizatoria del punto de vista occidental, véase, entre otras obras de obligada consulta, DE ROUGEMONT, D.; Tres milenios de Europa: la conciencia europea a través de los textos: de Hesíodo a nuestro tiempo [1961], Madrid, Veintisiete Letras, 2007; CHABOD, F.; Historia de la idea de Europa [1961], Madrid, Edersa, 1992; VOYENNE, B.; Historia de la idea de Europa [1964], Barcelona, Labor, 1970; MORIN, E.; Pensar Europa, Barcelona, Edicions 62, 1989; TUGENDHAT, C.; El sentido de Europa, Madrid, Alianza, 1986; FEBVRE, L.; Europa. Génesis de una civilización, Barcelona, Crítica, 2001.

${ }^{4}$ AA.VV.; ¿Dónde vas, Europa? (Miquel Seguró y Daniel Innerarity, eds.), Barcelona, Herder, 2017.

${ }^{5}$ Véase, por ejemplo, las diversas contribuciones al I Congrés de Qüestions de Vida Cristiana publicadas en AA.VV., Qüestions de Vida Cristiana. Europa: retrobar l'ànima, nº 253, 2015, Barcelona, Fundació Joan Maragall - PAM.
} 
teleológico que busca desvelar permanentemente el sentido del ser. Se trata pues de trabajar un conjunto irreductible de interpretaciones plurales y contextuales que solamente pueden ser universalizables mediante la competencia dialogal y el conflicto argumentativo. Desaparece, así, cualquier rastro de una universalidad abstracta de cuño racionalista. ${ }^{6}$

Fijada la cuestión del método, cabe ya establecer los objetivos de este artículo: primero, a partir del acervo común de los humanismos democráticos asentado tras la Segunda Guerra Mundial por el europeísmo político, establecer los valores y principios que, a modo de ética pública, deberían regir la imperiosa renovación del contrato sociopolítico de las democracias europeas; y segundo, diagnosticar algunos de los impedimentos a este deseable desarrollo de las democracias europeas provenientes tanto del pensamiento hegemónico neoliberal como de las variadas reacciones populistas e iliberales surgidas en su contra.

\section{Valores y principios del ethos europeo como fundamentos del contrato sociopolítico}

La pregunta es clara: ¿cuáles son los valores que han de sustentar el incierto futuro de la Europa del siglo XXI inmersa en un mundo multipolar en gestación? A nuestro entender, frente a la atomización neoliberal del individuo, o lo que sería lo mismo, frente a una Europa con déficit de ética pública compartida, Europa sí que puede ser un proyecto moral en base a una identidad enraízada y, a la vez, crítica y abierta a la interculturalidad. Nuestra propuesta, desde la revalorización de los humanismos políticos democráticos y el uso de una ética pública federalista, apuesta por no renunciar a consagrar en el derecho, tanto estatal como internacional, valores comunes como la preservación de la dignidad de todo ser humano y de sus derechos inherentes, el respeto a la ley, la protección de las minorias frente a las mayorías, la división del poder en un juego virtuoso de check and balance, la transparencia y la subsidiariedad institucionales, la equidad, la justicia social, la solidaridad recíproca o la paz. Se trata así, en definitiva, de abundar en un modelo de ética política y jurídica que busca la universalidad moral como meta, pero no desde la abstracción filosófica puramente formal o procedimental -que piensa "desde arriba" en clave de lógica deductiva-, sino partiendo de la especificidad de cada civilización o cultura humana -que piensa "desde abajo" en clave de lógica

\footnotetext{
6 "La hermenéutica sin un proyecto de liberación es ciega, pero un proyecto de emancipación sin experiencia histórica es vacuo." RICOEUR, P.; Ideología y utopía, Barcelona, Gedisa, 1994, p. 260.
} 
inductiva- y de la confrontación competitiva de argumentos plurales en aras de acrecer un humanismo democrático compartido.

Hay aquí una certeza moral de partida sobre el ser humano. La defensa de una visión antropológica que no es ni individualista (al estilo del liberalismo) ni colectivista (al modo sea del socialismo marxista sea del identitarismo cerrado y autorreferencial), sino más bien relacional e intersubjetiva, al estilo de los diversos personalismos comunitarios. Ya que se parte de la convicción de que el ser humano es persona en la medida que es un individuo en relación con los otros. Tanto María Zambrano como Hans Jonas lo han expresado muy bien en relación con el ethos humanista y democrático de Europa. La filósofa española, con acento orteguiano, al afirmar que "si se hubiera de definir la democracia podría hacerse diciendo que es la sociedad en la cual no sólo es permitido, sino exigido, el ser persona". ${ }^{7}$ Y el filósofo alemán cuando, buscando corregir los déficits de la Ilustración moderna mostrados por la experiencia del mal y de la vulnerabilidad humana a lo largo del siglo XX, dejó dicho: "la responsabilidad es la carga de la libertad". ${ }^{8}$

Estas ideas éticas y antropológicas pretenden exorcizar aquello que el naciente europeísmo político durante la inmediata segunda posguerra buscaba evitar a toda costa: "Es con el polvo de los individuos cívicamente irresponsables como los dictadores hacen su cimiento". ${ }^{9}$ Es precisamente el autor de esta última frase, el suizo Denis de Rougemont, uno de los padres intelectuales del ideario europeísta, el que, ante las cenizas de la ruina material y espiritual de Europa tras la conflagración bélica, mostró, junto a otros, la necesidad de ir al reencuentro del núcleo de principios axiológicos, siempre plural y en tensión creadora, surgido de la propia experiencia histórica del Viejo Continente. Una meditación sobre la matriz civilizatoria de Europa que el pensador helvético planteó a guisa de unidad poliédrica de variadas aportaciones culturales en medio de una fértil contradicción en tensión permanente, siguiendo una narratividad hermenéutica siempre abierta a nuevas contribuciones dentro

\footnotetext{
${ }^{7}$ ZAMBRANO, M.; Persona y democracia. La historia sacrificial [1958], Barcelona, Anthropos, 1988, p. 133. En cuanto al ideario político de Zambrano, conformado por un ethos democrático que persigue el fin último de la humanización de la sociedad y la personalización de los individuos, véase también RUBIO, J.; "Democracia personalizada versus partidocracia. Los problemas actuales de la democracia a la luz del pensamiento de María Zambrano", Educación moral, postmodernidad y democracia. Más allá del liberalismo y del comunitarismo, Madrid, Trotta, 2000, pp. 228-244.

8 JONAS, H.; El principio de responsabilidad. Ensayo de una ética para la civilización tecnológica, Barcelona, Herder, 1995.

${ }^{9}$ DE ROUGEMONT, D.; L'Europe en jeu [1948], Oeuvres complètes de Denis de Rougemont. Écrits sur l'Europe (Christophe Calame, ed. lit.), París, Éditions de la Différence, 1994, t. III, vol. I, pp. 31-32.
} 
de un proceso ininterrumpido. ${ }^{10}$ Sin duda, un primer y prematuro éxito de semejante vector políticocultural fue la creación del Consejo de Europa y su obra de protección de los derechos humanos a nivel continental, bajo la estela de la Declaración Universal de los Derechos Humanos de 1948 impulsada por la ONU en pro de la construcción de un nuevo Derecho Internacional de los Derechos Humanos.

A la luz de tales perspectivas sobre el carácter abierto, plural y dialógico de la historia cultural de Europa, ampliamente asentadas en el mundo intelectual, sorprende constatar como, tras la polémica no libre de cierto apasionamiento e incluso de algunos puntos de acritud- en torno a la cita expresa de las fuentes que dotan de contenido a la cultura europea en el texto del frustrado proyecto de Tratado por el que se instituye una Constitución para Europa (2003), en un último momento, la UE optó por ocultarlas conscientemente. Aún así, el texto final -rechazado en referéndum en diversos países y, por lo tanto, sin vigencia jurídica alguna- se redactó con un cierto acento rougemontiano, apelando en su preámbulo a una cultura europea "unida en la diversidad" y a un humanismo democrático sustentado sobre "las herencias culturales, religiosas y humanistas de Europa". Semejante posicionamiento se justificó entonces en razón de no obstaculizar, por un lado, la entrada de Turquía en la UE y, de otro lado, en base a no dificultar más aún el difícil acomodamiento del Islam europeo.

A pesar de todo, esta eliminación de todo referente histórico, conceptualmente argumentable, comporta, en opinión de Alain de Libera, unas graves consecuencias: la imposibilidad de pensar los problemas culturales y, consecuentemente, el impedimento a la reflexión filosófica, lo cual conduce a la instauración de unos orígenes míticos (o, peor, anónimos) para la Europa actual basada en los principios de la democracia y del Estado de Derecho. Y lo que es todavía menos deseable, queriendo escapar del choque de civilizaciones por medio de la amnesia voluntaria, los europeos se arriesgan a encaminarse hacia un choque de amnesias colectivas. Frente a tal desvarío, Libera considera mucho más provechosa la vía hacia la que tienden todos los esfuerzos de Rougemont. A saber, la construcción de un "universalismo concreto" que, desde la unidad de la razón y el reconocimiento de las raíces concretas de cada persona y de cada una de las comunidades humanas, permita configurar un "nosotros" que incluya de verdad al otro, haciendo del fundamento común de los derechos humanos la garantía de esa multiculturalidad. Esta meta no supone un nuevo "laicismo republicano a la francesa",

\footnotetext{
${ }^{10}$ Una exposición de los fundamentos culturales de Europa según este autor se puede encontrar tanto en DE ROUGEMONT, D.; L'un et le divers [1970], Oeuvres complètes..., op. cit., t. III, vol. II, pp. 239-240 y 244-245; como en La aventura occidental del hombre [1957], Buenos Aires, Sur, 1968.
} 
sino, más bien, una visión histórico-crítica de la propia modernidad (que la vuelva reflexiva sobre sus propios orígenes culturales y sus deficiencias estructurales) y el fomento de iniciativas como el diálogo interreligioso y el ecumenismo en el espacio público de la sociedad civil. ${ }^{11}$

Por su parte, Javier de Lucas, partiendo de la base de que la cohesión de toda comunidad sociopolítica requiere un imaginario cultural colectivo como fundamento, se muestra cercano a $\mathrm{D}$. de Rougemont o E. Morin cuando acepta que si se tiene que hablar de identidad cultural europea hay que hacerlo en términos de pluralidad integradora, abierta a la crítica y a la evolución histórica, nunca a título de una identidad unívoca y excluyente. Sin embargo, su punto de vista, incómodo frente a una adscripción sin matices a un "patriotismo constitucional o republicano" al estilo de Habermas, tiende a identificarse con la concepción "oficial" (más formalmente "procedimentalista", legalista y aisladora de los diferentes grupos humanos en clave de relativismo ético y cultural), criticada por de Libera. Así, para de Lucas,

"hay que apostar por la vía jurídica y política en lugar de encallarse en la imposible empresa de la recreación de la comunidad cultural europea, de la UE como comunidad cultural. En ese sentido parecía entenderlo la Carta de Niza primero y ahora el actual proyecto de Constitución [...]. La clave es ésta: la capacidad para transformar esa diversidad cultural en un marco jurídico y político que podríamos definir en términos de democracia plural e inclusiva."12

En definitiva, parece que en posiciones como la de J. de Lucas, bien contrastables en la izquierda europea, encontramos que, más allá de la lógica y el lenguaje jurídico-político de los derechos fundamentales de los ciudadanos y de la vida privada como ámbito genuino de la diferencia cultural, existen reticencias importantes a abrir la esfera de la ética pública a las interacciones y contradicciones que surgen en el debate entre distintos puntos de vista culturales y religiosos. Es decir, se detecta en este punto una cierta reserva desconfiada a dar el paso desde el modelo de multiculturalismo, con todos sus efectos contraproducentes en cuanto a falta de comunicación e intercambio entre culturas, a otro de interculturalidad más sincera y profundizada. Tal vez, la evolución vivida durante los últimos años por

\footnotetext{
${ }^{11}$ DE LIBERA, A.; “Europe plurielle: l'héritage anonyme”, Dialogue des cultures à l'aube du XXIème siècle. Hommage à Denis de Rougemont, Bruselas, Bruylant, 2007, pp. 73-81.

12 DE LUCAS, J.; “Identidad y Constitución Europea ¿Es la identidad cultural europea la clave del proyecto europeo?”, Europa: derechos, culturas, València, Universitat de València/Tirant lo Blanch, 2006, pp. 150-151.
} 
un autor tan relevante como el propio Habermas abra la puerta a una transformación de tales actitudes e ideas. Ya que el filósofo alemán, frente a la tradicional consideración de la religión y de las identidades comunitarias como atavismos irracionales o residuos premodernos tendencialmente eliminables por la modernidad sociopolítica, ha enmendado su visión para pasar a postular que son fundamentos prepolíticos importantes a la hora de crear solidaridades sociales y, por tanto, sustratos culturales presentes en la sociedad civil (requeridos de ser "traducidos" o formulados en el lenguaje racional y laico de la ética pública) que el posterior contrato sociopolítico tiene el deber de ayudar a preservar, sin que ello afecte a la laicidad o neutralidad del Estado en materia de valores sociales. ${ }^{13}$

Toda esta reflexión sobre el ethos político-cultural y jurídico de Europa y su necesaria articulación práctica nos lleva, en último término, a reivindicar la tradición de los humanismos democráticos aparejada a una cultura política federalista como fundamento de un nuevo contrato sociopolítico europeo. Pues, "Europa podrá reencontrarse, trascendiendo su des-unión, si apuesta por una economía solidaria, una democracia inclusiva, un compromiso serio con los derechos humanos y si se resitúa en el mundo abandonando el eurocentrismo del pasado". ${ }^{14}$ Así, frente a la ortodoxia neoliberal, hegemónica y unilateral, en concordancia con autores de distintas disciplinas como Miquel Seguró, Marina Garcés, Manuel Cruz, Ramón Cotarelo, Josep Ramoneda, Daniel Innerarity o Francesc Torralba, ${ }^{15}$ creemos que las instituciones europeas, y en especial la UE, están llamadas a afrontar al menos cuatro desafíos urgentes para concretar ese deseado y renovado contrato sociopolítico europeo.

En primer lugar, como base estructural imprescindible para permitir cambios en otros ámbitos, se requiere llevar a cabo las necesarias transformaciones económicas y financieras encaminadas hacia una optimización de la integración europea en clave de mutualización de la deuda de los Estados y armonización fiscal y bancaria. Cuestiones técnicas muy vinculadas al propio liberalismo económico, pero que, por otra parte, suponen ahondar en una gobernanza común entre los niveles de poder estatal y europeo en clave de "soberanías compartidas" o gobiernos multinivel.

\footnotetext{
${ }^{13}$ HABERMAS, J.; Entre naturalismo y religión, Barcelona, Paidós, 2006.

14 PÉREZ TAPIAS, J. A.; "La Europa desalmada", Ctxt. Revista Contexto, 15 de mayo de 2019 [consulta en Internet: 1/6/2019]: https:/ctxt.es/es/20190515/Firmas/26128/Jose-Antonio-Perez-Tapias-Europa-desalmada-libro-coleccion-contexto.htm

${ }^{15}$ SEGURÓ, M; "Punto de partida"; GARCÉS, M.; "Distancias próximas. Libertad y universalidad en un mundo común”; CRUZ, M.; "La política que viene y la política que se necesita"; COTARELO, R.; "La Europa realmente existente"; RAMONEDA, J.; "Las instituciones morales europeas"; INNERARITY, D.; "La promesa social europea"; TORRALBA, F.; "Conflicto axiológico y pluralidad espiritual en Europa”, ¿Dónde vas, Europa?, op. cit., pp. 15-41, 57-71, 87-99, 125-139, 157-170 y 217-231.
} 
En segundo lugar, se precisa profundizar en la salvaguarda y mayor garantía de los derechos sociales a nivel de un Welfare State de dimensión europea.

En tercer lugar, cabe proyectar el desarrollo de la participación democrática de la ciudadanía europea a través de estructuras federalistas y de subsidiariedad, que impulsen, sobre todo, el reconocimiento de las regiones como un tercer nivel de poder político en el seno de la UE frente a la tendencia al replegamiento recentralizador del Estado-nación.

En cuarto y último lugar, se debería ir madurando un modelo cultural de "universalismo concreto" como un nuevo sentido de vida comunitaria, que permita integrar la pluralidad social e identitaria (tanto de los europeos autóctonos como de los inmigrantes recién llegados). En pro de este patrón de "universalidad enraízada o contextualizada" cabe referir modelos normativos como la "comunión en la unidiversidad" postulada por August Monzon y Emilia Bea ${ }^{16}$ y la pluripertenencia identitaria a distintas comunidades de sentido (tanto de personas individuales como de grupos sociales) de Denis de Rougemont ${ }^{17}$, ambos ubicados dentro del universo de los personalismos comunitarios, o también, desde horizontes más procedimentalistas pero preocupados por tomarse en serio la diferencia cultural, el "cosmopolitismo de la diversidad compartida" teorizado por Ulrich Bech y Josep Ramoneda. ${ }^{18}$ En este sentido, comprender el ethos cultural europeo en términos de "universalidad concreta" nos lleva a atender las palabras de Lluís Duch:

"En $[\ldots]$ un diálogo entre las culturas que sea realmente fecundo y enriquecedor para todos, se tiene que mantener la tensión entre la parcialidad, es decir, la cultura concreta que sirve a cada uno de los partners para concretar y dar vida a su pensamiento, su acción y sus sentimientos, y la universalidad a la que todos aspiran, y que nunca dejará de ser una 'universalidad concreta' porqué para el ser humano [...] no hay posibilidad extracultural o, lo que es lo mismo, extragramatical."19

\footnotetext{
${ }^{16}$ MONZON, A.; "Liberalisme, comunitarisme, personalisme", Emmanuel Mounier i la tradició personalista, València, PUV, 2001, pp. 63-70.

${ }^{17}$ DE ROUGEMONT, D.; Lettre ouverte aux Européens [1970], Oeuvres complètes..., op. cit., t. III, vol. II, p. 333.

${ }^{18}$ RAMONEDA, J.; “L'esperit dual d'Europa”, Qüestions de vida cristiana. Europa: retrobar l'ànima, no 253, pp. 75-87.

${ }^{19}$ DUCH, LL.; "Diàleg entre cultures. Ficció i possibilitats", Afrontar la diversitat, Lleida, Pagès Editors, 2013, p. 36. La traducción al castellano es nuestra.
} 


\section{La tradición de los humanismos democráticos y la cultura política federalista como alternativa al neoliberalismo}

$\mathrm{Si}$, como apunta Hans Jonas, "la responsabilidad es la carga de la libertad", entonces razonablemente hay que optar por buscar vías para que los propios ciudadanos se hagan civícamente responsables de su futuro. Y para conseguirlo, cabe marcarse como meta un nuevo equilibrio entre, de una banda, la autonomía moral de la persona garantizada por sus derechos y libertades individuales y, de otra banda, su responsabilidad ética ante la comunidad social y el medio ambiente que la acoge a modo de hábitat humano. En consecuencia, como compensación reequilibradora al protagonismo excesivo de la economía en el modelo de globalización actual, potenciar la política y el civismo de la ciudadanía a título de elementos sanadores del tejido social se convierten en tareas ineludibles.

Semejante potenciación del polo cívico y político podría encontrar vías de implementación, según mi opinión, a través de tres instrumentos principales: una movilización democrática de la ciudadanía de carácter permanente e institucionalizado; la articulación de una ética pública de inspiración humanista y federalista; y la reformulación actualizadora de los plurales humanismos democráticos.

\subsection{Movilización ciudadana de carácter permanente e institucionalizado.}

A nivel de filosofía moral y política, cuando José Rubio Carracedo habla de una "democracia sin demócratas" o Victoria Camps de una "democracia sin ciudadanos" como patología padecida por la democracia liberal actual, en realidad, ambos están haciendo suyas las críticas recibidas por el pensamiento liberal a lo largo de las últimas décadas. Críticas que provienen tanto del comunitarismo neoconservador, difícilmente encajable con el pluralismo democrático, como del republicanismo y el personalismo comunitario, puntos de vista más humanistas y abiertos al diálogo permanente y sincero en perspectiva de perfeccionamiento de la cultura democrática. En todo caso, el diagnóstico es certero, ya que síntomas múltiples de la existencia de tal fenómeno sociopolítico no faltan: la desafección política, las actitudes incívicas, la clausura complaciente del ciudadano en el goce de la autonomía privada que le conceden los derechos y libertades reconocidos jurídicamente, el sentimiento de vacío respecto al papel de la ética pública frente a un Derecho sobredimensionado como razón normativa casi única o, incluso, la desmoralización ciudadana por falta de enraízamiento identitario en unas instituciones en ocasiones manchadas de descrédito o corrupción. Todo ello, en conjunto, muestra 
como uno de los retos de nuestros sistemas democráticos radica en la vertebración de una "ciudadanía moral", en la que los ciudadanos se sepan no sólo protegidos por unos derechos y libertades fundamentales, sino también llamados responsablemente al ejercicio de unos deberes cívicos de cooperación y solidaridad en beneficio del bien común. ${ }^{20}$

Esta tarea de regeneración de una ciudadanía más implicada en los asuntos públicos requiere, evidentemente, una movilización democrática de los ciudadanos de tipo permanente e institucionalizado, por medio de una activa e influyente sociedad civil que actúe como auténtico contrapoder respecto al Estado. Punto en el que es fundamental un sistema educativo comprometido con el fomento de las "virtudes públicas" mediante una educación ciudadana, así como también la salvaguarda de unos medios de comunicación independientes, con voz propia, y no sometidos a los intereses espurios del mundo económico-financiero.

Con ello, se evitaría o al menos se frenaría el impacto desmovilizador de la "doctrina del shock", según la cual, conforme indica Naomi Klein, cuando una sociedad es víctima de alguna catástrofe, bien de origen económico, político, violento o medioambiental, aquéllos que desean introducir políticas impopulares alejadas de una solución real al problema aprovechan el caos creado para tomar decisiones en contra del interés general de la población. La autora canadiense, desde un gran escepticismo crítico frente al pensamiento neoliberal, advierte que ese fenómeno de shock social puede venir impulsado premeditamente por lo que el economista Joseph Schumpeter calificó de forma eufemística, a mediados del siglo XX, como procesos de "destrucción creativa" del capitalismo. ${ }^{21}$

\subsection{Articulación de una ética pública de inspiración humanista y federalista.}

Con el objetivo claro de que la ciudadanía se empodere a sí misma, aplicando el principio de subsidiariedad que debe funcionar socialmente de abajo hacia arriba, ${ }^{22}$ es imprescindible que las

\footnotetext{
${ }^{20}$ Cf. RUBIO, J.; “¿Democracia sin demócratas? Paradigmas de la política y democracia”, Educación moral, postmodernidad y democracia..., op. cit., pp. 245-250. Y también AA.VV.; Democracia sin ciudadanos. La construcción de la ciudadanía en las democracias liberales (Victoria Camps, ed.), Madrid, Trotta, 2010.

${ }^{21}$ KLEIN, N.; La doctrina del shock: el auge del capitalismo del desastre, Barcelona, Paidós, 2012.

${ }^{22}$ El principio de subsidiariedad se entiende aquí como un criterio funcional de exacta adecuación o mayor eficacia a la hora de ajustar el nivel sociopolítico de decisión y actuación con la tarea encomendada a realizar, dando siempre prioridad al nivel de decisión más próximo al ciudadano para promocionar la participación democrática. Asimismo, cabe entender que el principio de subsidiariedad afecta al conjunto del espacio público en sentido amplio (tanto estatal como no estatal), comenzando por la sociedad civil, pasando por el Estado y llegando en último extremo a las organizaciones internacionales.
} 
personas reactualicen y fortalezcan, cuando no reconstruyan desde cero, sus círculos de relación y compromiso social y comunitario: desde la familia, el barrio, la localidad, la región, la nación y el Estado hasta llegar a ámbitos supraestatales en perspectiva cosmopolita.

De esta manera, en oposición al aislamiento individualista, la fragmentación social y la desafección política imperantes, se trata de promover un humanismo relacional, en el que el engranaje que constituye el binomio persona-comunidad permita, poco a poco, recoger y unir los fragmentos e ir construyendo un mosaico social siempre incompleto por definición, pero abierto a mayores cuotas de integración.

Aquí el sujeto político a promocionar es, sin duda, el del ciudadano consciente y comprometido en una red solidaria de acción social. Y la lógica de pensamiento social a practicar no es, evidentemente, ni la atomización neoliberal del individuo ni la dialéctica marxista de contradicción y lucha entre clases sociales, sino más bien una "dialéctica de contradicción en relación" con una búsqueda constante de nuevos equilibrios sociales en pro del bien común. En este tipo de dialéctica, lo fundamental cuando se acomete el análisis del conflicto social es la "relación en tensión" y la capacidad de reconduccion creadora y pacificadora de esa realidad conflictual por parte de las instituciones. Así, se reconoce la existencia de intereses de clase contrapuestos y se reclama un ajuste equilibrado entre ellos en beneficio del bien común. Esta dialéctica propia de una ética pública humanista y federalista se basa, por tanto, en valores de mediación, alianza y reconciliación que promueven el diálogo y la búsqueda constante de nuevos consensos sociales.

\subsection{Reformulación actualizadora de los plurales humanismos democráticos.}

Sobre la base de una ética pública de carácter humanista y federalista, que promueve una solidaridad social efectiva y el bien común como fines últimos, encuentra unas condiciones óptimas de desarrollo una cultura política federalista definida como filosofía política de las relaciones públicas. Es esta cultura política federalista la que constituye el marco adecuado para llevar a cabo una reformulación actualizadora de los plurales humanismos democráticos -antaño originadores de lo que se conoció como "el gran consenso de la segunda posguerra".

En opinión de Manuel Cruz, 
"en tiempos de volatilidad política, como la que nos ha tocado vivir, y de crisis de cualesquiera de las formas de grandes relatos, [...] la única propuesta que materializa, institucionalizándolo, el valor de la fraternidad es precisamente la del federalismo. Porque [...] se esfuerza por dotar a la fraternidad de contenido político. [...] Precisamente porque 'fraternidad' quiere decir universalización de la egaliberté republicana (Balibar dixit), en la medida en que [estos planteamientos] vienen cargados de empeño por la emancipación y de voluntad de cooperación, deberían estar llamados a ocupar un lugar prioritario en el escenario de la política actual." 23

En atención a estas ideas federalistas, a nuestro parecer, el objetivo clave pasa por una renovación del binomio democracia-federalismo, ${ }^{24}$ lo cual requiere la exigencia de dos condiciones: 1) Que el federalismo, más allá de llegar a ser una cultura jurídica en el constitucionalismo global, sea, sobre todo, en un marco más amplio, una filosofía política de las relaciones públicas in extenso. ${ }^{25}$ 2) Que esa deseable interrelación más estrecha entre democracia y federalismo se formule como profundización en unos humanismos democráticos de carácter relacional o dialógico, siempre abiertos a la formación de consensos en temas fundamentales.

Semejante estrechamiento conceptual entre democracia y federalismo reúne también la virtud de poder ser reforzado mediante otros factores de carácter sinérgico, a saber: por un lado, la necesidad de complementar las formas clásicas de democracia representativa con los mecanismos de democracia participativa (más abierta esta última a una mayor corresponsabilidad de los ciudadanos en los procesos de consulta y toma de decisiones públicas); por otro lado, la revitalización del anquilosado corporativismo liberal, que institucionaliza la representatividad horizontal de la sociedad civil ante las estructuras del Estado; y, finalmente, la consolidación técnica dentro de la ciencia política del tipo de gestión pública llamado "gobernanza democrática", que, en oposición a modelos anteriores como la

\footnotetext{
${ }^{23}$ CRUZ, M.; "La política que viene y la política que se necesita”, ¿Dónde vas, Europa?, op. cit., pp. 96-98.

${ }^{24}$ MARTÍNEZ I SEGUÍ, J. A.; "Filosofía política federalista y democracia: una ética pública humanista como vínculo", Federalismi.it. Rivista di Diritto Pubblico italiano, comparato, europeo, número especial 2/2018, 22 junio de 2018, pp. 2-13 [consulta en Internet: 1/6/2019]: http://federalismi.it/nv14/articolo-documento.cfm?Artid=36554

${ }^{25}$ Esta visión del federalismo se ve apoyada en autores como, por ejemplo, Miquel Caminal, para quien el federalismo no es solamente un constructo jurídico de Derecho constitucional, sino también, y de forma complementaria, una cultura política imprescindible para el funcionamiento de las federaciones. CAMINAL, M.; El federalismo pluralista. Del federalismo nacional al federalismo plurinacional, Barcelona, Paidós, 2002; y también "Nacionalismo liberal, federalismo pluralista y Estados plurinacionales", La teoría política frente a los problemas del siglo XXI, Granada, Universidad de Granada, 2004, pp. 145-165.
} 
burocracia estatalista (Max Weber) o la "nueva gestión pública" de inspiración neoliberal, defiende una "gestión relacional". 26

Además, no hay que olvidar que el federalismo en sí mismo, a modo de cultura política basada en el pacto entre individuos y entre colectividades, más allá incluso del marco estatal, atesora un gran potencial de influencia en lo referente a la articulación de instituciones internacionales con mayores cuotas de integración multilateral y supranacional. Tales instituciones de Derecho Internacional Público vendrían así a compensar la pérdida de poder estatal y ciudadano en manos de unos agentes económicos y financieros a menudo de perfil difuso, los cuales hacen peligrar la ya de por sí difícil garantía universal de los derechos humanos, cuando no actúan deliberadamente en su contra. En este sentido, el federalismo a nivel supraestatal (a ejemplo de la UE) se aprecia como un instrumento relevante a la hora de revalorizar el papel del Derecho positivo en el marco de la sociedad internacional con el fin de establecer límites y reglas al mercado capitalista a partir de la previa reflexión y decisión política.

En consecuencia, la regeneración del binomio democracia-federalismo podría contribuir a proyectar un horizonte posmoderno más esperanzador. Un horizonte en el que, por medio de una profundización en la cultura democrática de los derechos humanos, Europa (como espacio político más propenso a ello) y la humanidad en su conjunto puedan avanzar hacia una ponderación más equilibrada y justa entre el progreso material y el progreso moral.

En último término, sobre el sustrato de una cultura política federalista que renueve el binomio democracia-federalismo, queda por contestar la pregunta sobre cómo repristinar en nuestro contexto actual la tradición de los humanismos democráticos de la segunda posguerra. Lo cual, a mi entender, pasa, con mucho esfuerzo, por interpretar y recontextualizar fuentes clásicas e ideas-fuerza propias o próximas a cada uno de estos humanismos democráticos. En este sentido, humildemente, sólo me atreviría aquí a aportar algunas notas orientativas en referencia al liberalismo progresista, la socialdemocracia y la democraciacristiana.

\footnotetext{
${ }^{26}$ Cabe destacar como el modelo de "gobernanza democrática" supone una gestión pública en red basada en estrategias y metodologías de desarrollo bottom up, de abajo hacia arriba, más horizontales, más participativas y colaborativas, que empoderan a las personas individuales y a las comunidades, dotan el ejercicio del autogobierno de mayor trasparencia y responsabilidad y permiten integrar mejor lo local en lo global. En definitiva, este modelo de "gobernanza democrática" acerca las técnicas de la ciencia política a principios federalistas y de subsidiariedad propios de la filosofía política. Cf. AA.VV.; Gobernanza democrática (Antonio Rovira, coord.), Madrid, Marcial Pons, 2013
} 
En cuanto al liberalismo político en su conjunto, más allá del rechazo crítico a la radicalidad libertaria del modelo neoliberal, no comparto la tesis de Nancy Fraser, pensadora de la izquierda norteamericana, según la cual el liberalismo progresista, que ella identifica con figuras como Barack Obama, los Clinton, Madeleine Albright o Tony Blair, estaría ya agotado y debería ser amortizado por completo. ${ }^{27}$ En mi opinión, en oposición al núcleo duro de las teorías neoliberales -Ludwig von Mises, Friedrich Hayek, Milton Friedman y la Escuela de Chicago-, desde dentro del propio liberalismo progresista, cabe poner en valor el legado que va desde los economistas William Beveridge y John Maynard Keynes hasta el filósofo político John Rawls, pasando por el ordoliberalismo alemán.

En lo referente a la socialdemocracia, apuntaría dos desviaciones distorsionadoras bien presentes: por una banda, hacia la derecha, esto es, su vampirización dilutiva acaecida en gran medida a través de la llamada "tercera vía" impulsada por Tony Blair, que ha desvirtuado el discurso socialdemócrata al aproximarlo en exceso al liberalismo progresista hasta hacerlo casi irreconocible; y, por otra banda, hacia la izquierda, en cuyo caso cabe subrayar la tentadora atracción hacia un populismo de carácter izquierdista. Como bien indica José Antonio Pérez Tapias, la socialdemocracia debe renovarse a partir de la recuperación del espíritu de justicia social, de la búsqueda de una equitativa relación entre libertad e igualdad por medio de la solidaridad y de una apertura hacia la cultura política federalista, que le permita comprender la pluralidad como tensión entre la unidad y la diversidad. ${ }^{28}$ En esta tarea, las fuentes doctrinales que se encuentran en la Escuela de Frankfurt, el republicanismo, a buen seguro el pensamiento ecologista y, a nivel español, los demócratas federalistas del siglo XIX y XX (F. Pi i Margall...), pueden ser muy útiles para la reelaboración de los postulados socialdemócratas.

Por último, en lo que respecta a la democraciacristiana, salvo honrosas excepciones y múltiples resistencias en el panorama político europeo, hay que tener en cuenta un hecho crucial y dominante: la dilución y sustitución progresivas de su discurso genuino por parte del pujante neoconservadurismo desde principios de la década de 1980. Aún así, las potencialidades nada desdeñables de un discurso

\footnotetext{
${ }^{27}$ FRASER, N.; "El final del neoliberalismo progresista", Ctxt. Revista Contexto, no 101, 25 de enero de 2017 [consulta en Internet: 1/6/2019]: https://ctxt.es/es/20170125/Firmas/10572/Neoliberalismo-progresista-democratas-Hillary-Clinton-Nancy-Fraser.htm

${ }^{28}$ PÉREZ TAPIAS, J. A.; "Reivindicación del republicanismo", Ctxt. Revista Contexto, no 169, 21 de mayo de 2018 [consulta en Internet: 1/6/2019]: https:/ctxt.es/es/20180516/Firmas/19698/Reivindicacion-republica-democracia-Perez-Tapias.htm

Y también del mismo autor: "Republicanismo frente a populismo en el debate de la izquierda", Ctxt. Revista Contexto, $\mathrm{n}^{\circ} 183,22$ de agosto de 2018 [consulta en Internet: 1/6/2019]: https://ctxt.es/es/20180822/Firmas/21286/jose-antonio-perez-tapias-populismo-ideasocialista-republicanismo.htm
} 
socialcristiano de vocación netamente centrista están sólidamente asentadas sobre un elaboradísimo pensamiento humanista de larga tradición. Tanto es así que las corrientes del humanismo cristiano y de los variados personalismos comunitarios, que se mueven en una misma órbita filosófica, son, ciertamente, las más cercanas y propensas al cultivo de una cultura política federalista que desarrolle el principio de subsidiariedad, con gran preocupación, además, por la cuestión de la justicia social. En esta línea, cabe profundizar ideas socialcristianas, como las del propio Papa Francisco, tendentes tanto hacia una interculturalidad abierta, diálogica y dinámica, como hacia la promoción de la soberanía reguladora del Derecho en un mundo globalizado. ${ }^{29}$ Tal vez, el impedimento que más obstaculiza la regeneración de las ideas democristianas seguramente sea el fomento de un identitarismo cerrado y excluyente, auspiciado por sectores neoconservadores en el seno de los partidos democratacristianos europeos.

\section{Neoliberalismo global y reacciones políticas populistas, autoritarias e iliberales: impedimentos a una regeneración de las democracias europeas}

En la actualidad, lejos de aquel gran consenso democrático de la segunda posguerra que puso a Europa de nuevo en pie con justicia social y reconomiento de amplios derechos para la persona, nos vemos apremiados por una grave desarticulación ideológica (más real que no el tajante y determinista pronóstico de Francis Fukuyama de un final irremisible de las ideologías tras la Guerra Fría). ${ }^{30}$ Pero también nos vemos bloqueados por la creciente desafección ciudadana hacia los engranajes institucionales de la democracia representativa y la cultura política de partidos. Asimismo, nos vemos asustados por los tambores de guerra del llamado por Samuel P. Huntington "choque de civilizaciones". ${ }^{31}$ Semejantes problemáticas, analizadas desde el solar del Viejo Continente, nos hacen volvernos conscientes de una de sus principales raíces comunes en el campo sociopolítico: la carencia debilitadora en lo que respecta al cultivo de una ética pública vertebradora del ethos político-cultural europeo. Una cuestión especialmente lacerante e hiriente cuando, ante los retos de una globalización en marcha hacia una sociedad internacional multipolar formada por grandes espacios de envergadura

\footnotetext{
${ }^{29}$ DALLA TORRE, G.; "Il diritto secondo Papa Francesco", Studium, no 3, mayo-junio de 2018, p. 327.

${ }^{30}$ FUKUYAMA, F.; El fin de la Historia y el último hombre, Barcelona, Planeta, 1992.

${ }^{31}$ HUNTINGTON, S.; El choque de civilizaciones y la reconfiguración del orden mundial, Barcelona, Paidós, 1997.
} 
continental, el europeísmo político y la UE, una de sus principales instituciones existentes, se ven atrapados en una especie de marasmo inducido por la lógica neoliberal y tecnocrática.

4.1 El neoliberalismo global: marco adverso a una vindicación del ethos político-cultural europeo

En el paso del siglo XX al XXI, la expansión dominante de la globalización de inspiración neoliberal ha propiciado, en palabras de Zygmunt Bauman, una sociedad posmoderna de carácter "líquido", inmersa en una creciente "incertidumbre vital" y marcada, por tanto, por el aislamiento de los individuos y la fragmentación sociocultural. ${ }^{32}$ Desasido en gran medida de aquellas sólidas estructuras e instituciones sociales que antaño le daban mayor protección, el individuo vive su condición humana de forma más vulnerable y frágil, presa de los efectos de tal atomización social.

Esta atomización del tejido social, sin duda alguna, se ve favorecida en el campo de los valores morales por el relativismo ético y cultural a título de subjetivismo moral extremo (todo "depende" del punto de vista aislado de cada individuo, sin posibilidad de objetivación de criterios éticos comunes). Un relativismo ético que ejerce un predominio dentro de nuestra cultura popular de masas y, consecuentemente, obstaculiza, cuando no impide, la búsqueda de una ética pública de mínimos como base legitimadora de la cultura política y jurídica de los derechos humanos.

No obstante, en un medio social tan mercantilizado como en el que vivimos, el propio mercado capitalista hace las veces de vínculo cultural fuertemente unificador y estandarizador mediante la extensión del consumismo capitalista, que, en razón de su propia lógica interna, sólo auspicia el desarrollo de "diferencias comercializables". Hay aquí, como diría Jesús Ballesteros, una exaltación idealizada de la voluntad individual y del principio hedonista del placer donde el modelo de homo aconomicus se funde con el de homo ludens. ${ }^{33}$ Lo que, en medio de un invidualismo feroz y rampante, conlleva aparejado un olvido del sentido del deber frente al otro, una disolución del reconocimiento moral de la alteridad y de la diferencia de los otros seres humanos. Y, como última consecuencia, tal dilución de los vínculos de responsabilidad de la persona ante la comunidad social degrada y precariza al extremo la dimensión institucional imprescindible para la acción política.

\footnotetext{
${ }^{32}$ BAUMAN, Z.; Modernidad líquida, Madrid, Fondo de Cultura Económica de España, 2017.

${ }^{33}$ BALlesteros. J.; Postmodernidad: decadencia o resistencia, Madrid, Tecnos, 1997, pp. 85-98.
} 
En este marco de coordenadas de la cultura neoliberal posmoderna, la cándida y confiada sublimación de la tecnología - en materias como las neurociencias, las biotecnologías, la digitalización y la robotización- conduce incluso a una mayor y desmesurada exaltación individualista de la voluntad humana. Así, desde finales de los años 1990, se ha postulado una utopía futurista denominada "transhumanismo o posthumanismo", que, a guisa de nueva ideología tecnocéntrica, pretende la mejora de las cualidades y capacidades del ser humano a nivel genético, físico y psíquico para convertirlo en un ser mucho más perfeccionado de lo que naturalmente es; para que sea, de esta manera, más competente y competitivo. El prefijo trans- de transhumanismo apunta-sin dudarlo (y esto es lo más peligroso)- hacia la superación del humanismo del siglo XX, es decir, hacia la implementación de la tecnología no sólo con fines terapéuticos o de mejora de las capacidades naturales del ser humano (lo cual es aceptado de buena gana por toda filosofía humanista), sino también con fines "creadores o demiúrgicos" (unidos a una idea naif de progreso, ciega ante el dominio acaparador del avance tecnológico por parte de las élites sociales). ${ }^{34}$

Por último, para acabar de sintetizar algunos de los impedimentos más destacados que genera el pensamiento único neoliberal frente a la posibilidadad de regenerar el ethos humanista europeo en provecho de un nuevo contrato sociopolítico, debemos consignar la cuestión del trasfondo socioeconómico de la ciudadanía. Pues, lejos del ideal de una sociedad justa propio de un humanismo con vocación universalista y en auspicio de una idea de trabajo en la que el ser humano se convierte en un auténtico animal laborans -"verdugo y víctima de sí mismo"35-, el discurso hegemónico neoliberal se muestra insensible a los pujantes procesos sociales de desigualdad y exclusión que el mismo impulsa en todo espacio geográfico. Con ello, induce a la silenciosa y progresiva "desactivación" de la capacidad emancipadora de la cultura ética, política y jurídica de los derechos humanos. Ya que, a tenor de la línia interpretativa trazada por Max Weber y después proseguida por Max Horkheimer y Theodor W. Adorno ${ }^{36}$, la actual globalización socioeconómica y técnica (guiada por una razón meramente instrumental) no se identifica mayormente con la universalización moral y jurídica de los derechos humanos, a pesar de ser, ambos procesos, ramas del tronco común moderno. Así, en palabras

34 Cf. TORRALBA, F.; Humanisme, transhumanisme $i$ posthumanisme. Assaig de discerniment, Barcelona, Fundació Joan Maragall/Editorial Claret, 2016; y también SOMMAGGIO, P.; "La nuova demiurgia. Biotecnologie, postumano e società", Sociologia del Diritto, $\mathrm{n}^{\circ} 2,2018$, pp. 7-33.

${ }^{35}$ HAN, B.-Ch., La sociedad del cansancio, Herder, Barcelona, 2012.

${ }^{36}$ HORKHEIMER, M. y ADORNO, Th.; Dialéctica de la Ilustración: fragmentos filosóficos, Madrid, Trotta, 2003. 
de Javier de Lucas, mientras la lógica de la primera restringe y concentra el reconocimiento y goce de las libertades, la segunda expande y amplia los derechos desde una visión crítica, emancipadora y reivindicativa. ${ }^{37}$

\subsection{Los peligros de distintos extravíos sociopolíticos: las reacciones políticas populistas, autoritarias e iliberales}

Ante este panorama tremendamente complejo, fruto de una perspectiva economicista desbordada, de una antropología filosófica profundamente individualista, del debilitamiento de la clase media abocada a una precarización alarmante de las condiciones de vida y, en fin, de la falta de respuestas eficaces por parte de los partidos tradicionales, surgen apremiantes extravíos sociopolíticos a título de reacción instintiva o incluso visceral. Se trata de rechazos directos y sin paliativos al modelo neoliberal que impelen hacia peligrosos derroteros sociales. De esta manera, frente a un cierto ocaso de la política anclada en valores humanistas y razonamientos argumentados, se generan discursos y actitudes antipolíticas, que alimentan la crispación y la polarización sociopolítica.

El fundamentalismo religioso es uno de esos casos, no sólo el islámico con sus fanáticas derivas de violencia y crueldad radical, sino también, en menor medida, el cristiano y el hindú con manifestaciones de tipo más institucionalizado.

Pero también se incluye aquí el falaz y crispador "realismo" neoconservador, que, en camino hacia el autoritarismo desacomplejado, incentiva el descrédito de la reflexión política racional y razonada, apela a la emoción puramente irracional y al sentimiento comunitario más elemental de enfrentamiento entre un "nosotros" y un "ellos" y usa descaradamente las fake news bajo el paraguas legitimador de la "posverdad". ${ }^{38}$

\footnotetext{
${ }^{37}$ DE LUCAS, J.; "La globalización no significa universalidad de los derechos humanos. (En el 50 aniversario de la Declaración del 48)”, Jueces para la Democracia, no 32, julio de 1998, pp. 3-9.

${ }^{38}$ Es curioso constatar la contradicción flagrante entre medios y fines en la que incurre el discurso neocons cuando usa el espantajo demagógico de la denominada "posverdad". Pues la "posverdad", como estrategia dialéctica que busca la validación de informaciones sesgadas o directamente falaces mediante la repetición indiscriminada y el dominio de los mass media sobre una opinión pública preñada de relativismo o subjetivismo ético, choca de bruces con el identitarismo cerrado y el dogmatismo moral de "la verdad de unos valores únicos y auténticos” de los que parten las ideas neoconservadoras.
} 
Y, por supuesto, también cabría englobar en este paradigma de alarmantes extravíos sociopolíticos en expansión la amalgama de variados populismos políticos, ${ }^{39}$ tanto los ligados a la derecha neoconservadora cuando no directamente fascista, ${ }^{40}$ como los promovidos por la izquierda más alternativa. Respecto a esta última, cabe resaltar como dicha izquierda populista centra su discurso en el sujeto político "pueblo", a modo de una nueva "masa amorfa" o círculo continente sin contenido definido donde la diversidad social, víctima de la globalización neoliberal, se amontona sin orden ni concierto. En este sentido, Jorge Alemán, comentando las ideas postmarxistas y postestructuralistas de Ernesto Laclau, comenta lo siguiente:

"Una izquierda para la que la palabra revolución y su sujeto histórico ya no tienen eficacia simbólica alguna y, por tanto, la nueva radicalidad, el ir 'a la raíz de las cosas' es pensar una nueva lógica emancipatoria, puesto que ya no dispone de entrada de un sujeto asegurado. En definitiva, el proyecto populista emancipador debe intentar inventar y construir un sujeto con todos aquellos que son alcanzados por la terrible erosión de los vínculos sociales generados por la marcha incesante del capitalismo." ${ }^{41}$

Todos estos populismos, ya sea en la estridente versión neocons de la red paneuropea The Mouvement de Steve Bannon, ya sea en la versión más intelectual y altermundista de Ernesto Laclau y Chantal Mouffe $\mathrm{e}^{42}$, tienen ineludiblemente en común algunos aspectos centrales: primero, la búsqueda obsesiva de la hegemonía política unilateral frente a las políticas pluralistas de diálogo y consenso; segundo, la tendencia mayor o menor hacia "democracias iliberales" o de baja calidad entendidas a modo de separación conceptual entre democracia y liberalismo, que da como resultado la imposición creciente de la voluntad de la mayoría y la erosión de la doctrina liberal del gobierno limitado, de la separación de poderes dentro del Estado de Derecho, de las garantías de los derechos y libertades

\footnotetext{
${ }^{39}$ Véase el monográfico dedicado a los populismos en Anales de la Cátedra Francisco Suárez. Revista de filosofía jurídica y política, $\mathrm{n}^{\circ}$ 53, 2019 [consulta en Internet: 1/6/2019]: http://revistaseug.ugr.es/index.php/acfs/issue/view/585/showToc

40 LASSALLE, J. Ma; "Vox o la brutalidad política", La Vanguardia, 19 de enero de 2019 [consulta en Internet: 1/6/2019]: https://www.lavanguardia.com/opinion/20190119/454199430391/vox-o-la-brutalidad-politica.html

41 ALEMÁN, J.; "El concepto de populismo: una posición", Público, 18 de noviembre de 2016 [consulta en Internet: 1/6/2019]: https://blogs.publico.es/dominiopublico/18493/el-concepto-de-populismo-una-posicion/

${ }^{42}$ LACLAU, E. y MOUFFE, CH.; Hegemonía y estrategia socialista: hacia una radicalización de la democracia, México, Fondo de Cultura Económica, 2014.
} 
individuales y del respeto a las instituciones independientes de carácter contramayoritario; ${ }^{43}$ y en tercer y último lugar, el ideal de un soberanismo estatal de retorno nostálgico hacia la seguridad centralizadora del Estado-nación, aún siendo conscientes de la imposibilidad de tal promesa en un mundo cada vez más interconectado a velocidad de vértigo.

43 TOSCANO, M.; “¿Democracia 'iliberal’?”, Vozpópuli, 7 de septiembre de 2018 [consulta en Internet: 1/6/2019]: https://www.vozpopuli.com/opinion/democracia-iliberal-antiliberal-viktor-orban_0_1170184144.html 


\section{Bibliografía}

ALEMÁN, J.; “El concepto de populismo: una posición”, Público, 18 de noviembre de 2016. $<$ https://blogs.publico.es/dominiopublico/18493/el-concepto-de-populismo-una-posicion/>

AA.VV.; Anales de la Cátedra Francisco Suárez. Revista de filosofía jurídica y política. Populismos, nº 53, 2019. $<$ http://revistaseug.ugr.es/index.php/acfs/issue/view/585/showToc $>$

AA.VV.; Democracia sin ciudadanos. La construcción de la ciudadanía en las democracias liberales (Victoria Camps, ed.), Madrid, Trotta, 2010.

AA.VV., ¿Dónde vas, Europa? (Miquel Seguró y Daniel Innerarity, eds.), Barcelona, Herder, 2017.

AA.VV.; Gobernanza democrática (Antonio Rovira, coord.), Madrid, Marcial Pons, 2013.

AA.VV., Qüestions de Vida Cristiana. Europa: retrobar l'ànima, nº 253, 2015, Barcelona, Fundació Joan Maragall - PAM.

BALLESTEROS, J.; Postmodernidad: decadencia o resistencia, Madrid, Tecnos, 1997.

BAUMAN, Z.; Modernidad líquida, Madrid, Fondo de CulturaEconómica de España, 2017.

CAMINAL, M.; El federalismo pluralista. Del federalismo nacional al federalismo plurinacional, Barcelona, Paidós, 2002.

CAMINAL, M.; "Nacionalismo liberal, federalismo pluralista y Estados plurinacionales", La teoría política frente a los problemas del siglo XXI, Granada, Universidad de Granada, 2004.

CHABOD, F.; Historia de la idea de Europa [1961], Madrid, Edersa, 1992.

DALLA TORRE, G.; "Il diritto secondo Papa Francesco", Studium, n 3, mayo-junio de 2018.

DE LIBERA, A.; “Europe plurielle: l'héritage anonyme”, Dialogue des cultures à l'aube du XXIème siècle. Hommage à Denis de Rougemont, Bruselas, Bruylant, 2007.

DE LUCAS, J.; "La globalización no significa universalidad de los derechos humanos. (En el 50 aniversario de la Declaración del 48)", Jueces para la Democracia, nº 32, julio de 1998.

DE LUCAS, J.; “Identidad y Constitución Europea ¿Es la identidad cultural europea la clave del proyecto europeo?”, Europa: derechos, culturas, València, Universitat de València/Tirant lo Blanch, 2006.

DE ROUGEMONT, D.; La aventura occidental del hombre [1957], Buenos Aires, Sur, 1968.

DE ROUGEMONT, D.; Tres milenios de Europa: la conciencia europea a través de los textos: de Hesiodo a nuestro tiempo [1961], Madrid, Veintisiete Letras, 2007.

DE ROUGEMONT, D.; Oeuvres complètes de Denis de Rougemont. Écrits sur l'Europe (Christophe Calame, ed. lit.), París, Éditions de la Différence, 1994.

DUCH, LL.; "Diàleg entre cultures. Ficció i possibilitats", Afrontar la diversitat, Lleida, Pagès Editors, 2013.

FEBVRE, L.; Europa. Génesis de una civilización, Barcelona, Crítica, 2001.

FRASER, N.; "El final del neoliberalismo progresista", Ctxt. Revista Contexto, no 101, 25 de enero de 2017. $<$ https://ctxt.es/es/20170125/Firmas/10572/Neoliberalismo-progresista-democratas-Hillary-Clinton-Nancy-Fraser.htm>

FUKUYAMA, F.; El fin de la Historia y el último hombre, Barcelona, Planeta, 1992.

HABERMAS, J.; Entre naturalismo y religión, Barcelona, Paidós, 2006.

HAN, B.-Ch.; La sociedad del cansancio, Herder, Barcelona, 2012.

HORKHEIMER, M. y ADORNO, Th.; Dialéctica de la Ilustración: fragmentos filosóficos, Madrid, Trotta, 2003. 
HUNTINGTON, S.; El choque de civilizaciones y la reconfiguración del orden mundial, Barcelona, Paidós, 1997.

JONAS, H.; El principio de responsabilidad. Ensayo de una ética para la civilización tecnológica, Barcelona, Herder, 1995.

KLEIN, N.; La doctrina del shock: el auge del capitalismo del desastre, Barcelona, Paidós, 2012.

LACLAU, E. y MOUFFE, CH.; Hegemonía y estrategia socialista: hacia una radicalización de la democracia, México, Fondo de Cultura Económica, 2014.

LASSALlE, J. Ma; "Vox o la brutalidad política", La Vanguardia, 19 de enero de 2019. $<$ https://www.lavanguardia.com/opinion/20190119/454199430391/vox-o-la-brutalidad-politica.html>

MARTÍNEZ I SEGUÍ, J. A.; "Filosofía política federalista y democracia: una ética pública humanista como vínculo", Federalismi.it. Rivista di Diritto Pubblico italiano, comparato, europeo, número especial 2/2018, 22 junio de 2018. $<$ http://federalismi.it/nv14/articolo-documento.cfm?Artid=36554>

MASDEU, J.; "Franz Tirmmermans, el holandés que quiere reformar Europa", La Vanguardia, 18 de mayo de 2019. $<$ https://www.lavanguardia.com/internacional/20190518/462299422232/franz-timmermans-europa-comision-europeaelecciones.html>

MONZON, A.; "Liberalisme, comunitarisme, personalisme”, Emmanuel Mounier i la tradició personalista, València, PUV, 2001.

MORIN, E.; Pensar Europa, Barcelona, Edicions 62, 1989.

PÉREZ TAPIAS, J. A.; "Reivindicación del republicanismo", Ctxt. Revista Contexto, no 169, 21 de mayo de 2018. $<$ https://ctxt.es/es/20180516/Firmas/19698/Reivindicacion-republica-democracia-Perez-Tapias.htm>

PÉREZ TAPIAS, J. A.; "Republicanismo frente a populismo en el debate de la izquierda", Ctxt. Revista Contexto, n 183, 22 de agosto de 2018. <https://ctxt.es/es/20180822/Firmas/21286/jose-antonio-perez-tapias-populismo-idea-socialistarepublicanismo.htm>

PÉREZ TAPIAS, J. A.; "La Europa desalmada”, Ctxt. Revista Contexto, 15 de mayo de 2019. <https://ctxt.es/es/20190515/Firmas/26128/Jose-Antonio-Perez-Tapias-Europa-desalmada-libro-coleccion-contexto.htm>

RAMONEDA, J.; “L'esperit dual d'Europa”, Qüestions de vida cristiana. Europa: retrobar l'ànima, no 253.

RICOEUR, P.; Ideología y utopía, Barcelona, Gedisa, 1994.

RUBIO, J.; Educación moral, postmodernidad y democracia. Más allá del liberalismo y del comunitarismo, Madrid, Trotta, 2000 .

SOMMAGGIO, P.; “La nuova demiurgia. Biotecnologie, postumano e società”, Sociologia del Diritto, nº 2, 2018.

TORRALBA, F.; Humanisme, transhumanisme i posthumanisme. Assaig de discerniment, Barcelona, Fundació Joan Maragall/Editorial Claret, 2016.

TOSCANO, M.; “Democracia ‘iliberal’?”, Vozpópuli, 7 de $\quad$ septiembre de 2018. <https://www.vozpopuli.com/opinion/democracia-iliberal-antiliberal-viktor-orban_0_1170184144.html>

TUGENDHAT, C.; El sentido de Europa, Madrid, Alianza, 1986.

VOYENNE, B.; Historia de la idea de Europa [1964], Barcelona, Labor, 1970.

ZAMBRANO, M.; Persona y democracia. La historia sacrificial [1958], Barcelona, Anthropos, 1988.

ZAMBRANO, M; La agonía de Europa, Madrid, Trotta, 2000.

CEFD Número 40 (2019) I ISSN: 1138-9877 I DOI: 10.7203/CEFD.40.13932 